\title{
Phytoestrogens as Nutritional Modulators in Colon Cancer Prevention
}

\author{
Michele Barone, Raffaele Licinio and Alfredo Di Leo \\ Gastroenterology Unit, Department of Emergency and \\ Organ Transplantation (D.E.T.O.), University of Bari "A. Moro", Bari,
}

Italy

\section{Introduction}

Intestinal carcinogenesis is the final outcome of a multi-step process resulting from genetic alterations that are influenced by two categories of factors: environmental factors and hostrelated factors such as cytokines and hormones (including sex steroid hormones). One of the most important environmental factors involved in the development of colon cancer is dietary components. However, variations in cancer incidence among and within populations with similar dietary patterns suggest that the predominant pathogenetic factor is the individual response, through the expression of different protein and metabolite patterns (1). Among host-related factors particular attention is paid in this work to the relationship between estrogens, as well as their agonists (phytoestrogens), and colon cancer, and the possible role of these latter substances in the prevention of colon cancer.

\section{APC gene in colorectal cancer}

Colorectal cancer (CRC) is the final outcome of a multi-step process that, in most cases, proceeds down the adenoma-carcinoma sequence pathway (2).

The tumor suppressor gene mutation involving the Adenomatous Polyposis Coli (APC) gene is present in $80 \%$ of sporadic CRCs and $100 \%$ of cases of Familial Adenomatous Polyposis (FAP). In humans, the APC mutation provides the genetic background to the onset of the tumor process, making intestinal cells susceptible to tumor progression and promotion through the accumulation of further mutations as a result of epigenetic phenomena largely influenced by environmental factors (3).

FAP offers an ideal model for the study of CRC since in these patients "normal" mucosa coexists with low and high-grade dysplastic lesions as well adenocarcinoma, i.e. all the stages of the carcinogenetic process. For this reason the modifications occurring during the carcinogenetic process are easily comparable and free from individual variations (4).

\section{Estrogens in colorectal cancer}

Phytoestrogens (heterocyclic non steroid phenols) are plant-derived compounds with a structural and functional action as estrogen agonists in mammals. To understand their 
biological activities and the possible interactions between phytoestrogens and colorectal cancer, a knowledge of some fundamental data on estrogens is essential.

Estrogen biological activities are mainly mediated by their binding with two specific receptors: estrogen receptor alpha (ER- $\alpha$ ) and estrogen receptor beta (ER- $\beta$ ). Both of these estrogen receptors (ERs) belong to the steroid/thyroid hormone receptor superfamily of nuclear receptors, which are activated upon binding of the ligand. After binding, activated ERs are able to interact directly with cis-regulatory elements of target genes by binding to estrogen-response elements (EREs), or indirectly through interaction with another DNAbound transcription factor, such as activator protein 1 (AP-1), thus facilitating the assembly of basal transcription factors into a stable pre-initiation complex, followed by increased transcription rates for target mRNAs (5).

Both ERs consist of three main regions: 1) a hypervariable N-terminal, that contributes to the transactivation function, 2) a highly conserved DNA-binding domain, responsible for specific DNA-binding and dimerization and 3) a C-terminal domain, involved in ligandbinding (LBD) and nuclear localization, as well as ligand-dependent transactivation functions. ER- $\alpha$ and ER- $\beta$ are produced by different genes located on different chromosomes (6).

In mammals, both ER-a and ER- $\beta$ have conserved DNA binding domains (96\%) but they have different LBD showing only 58\% homology. ER-a has two distinct transcriptional activation functions (AF): AF-1 and AF-2. AF-1, located at the N-terminal, is ligandindependent, constitutively active and contributes to the transcriptional activity of the receptor by recruiting co-activator proteins such as GRIP1 and SRC-1 and the histone acetyltransferases (HAT) p300/CBP and pCAF. The AF-2 domain is under the control of ligands in both ER- $\alpha$ and ER- $\beta$.

Variations observed in the phenotypes of knock-out mice lacking ER-a or ER- $\beta$ suggest that these two proteins have different biological activities. This view has been further supported by in vitro and in vivo studies in ER- $\beta$ knock-out mice, indicating that ER- $\beta$ is a modulator of ER- $\alpha$ activity as it is able to reverse the effects of ER- $\alpha$ and to inhibit estradiol $\left(E_{2}\right)-$ dependent proliferation (7). In addition, it is known that ER-a and ER- $\beta$ have a different distribution in the various organs and apparatuses. ER- $\alpha$ is essentially expressed in the breast, bone, cardiovascular tissue, urogenital tract and central nervous system, while ER- $\beta$ is the prevalent form in the gut. Both receptors bind $E_{2}$ but they activate promoters in different ways. Studies on breast and prostate carcinogenesis suggest an opposite role of ER$\alpha$ and ER- $\beta$ in the proliferation and differentiation of target tissues, a hypothesis described as the ying/yang relationship (8).

Estrogens regulate cellular function also through non-genomic pathways. In fact, after palmitoylation ERs can localize at the plasma membrane, associate to caveolin-1 and, upon estrogens stimulation, activate rapid signals. In the case of ER- $\alpha$, palmitoylation stimulates proliferation, while ER- $\beta$ localization at the plasma membrane and its association with caveolin-1 activates p38 (a member of the MAPK family), that promotes apoptosis (9). This finding is confirmed by the observation, in the tumor tissue, of a reduction of ER- $\beta$ and an increased alpha/beta ratio, that is related to a reduction of apoptosis and an increased rate of proliferation. 
In the last few years, numerous epidemiological, clinical and experimental studies have explored the role of estrogens in intestinal carcinogenesis, suggesting their protective role and potential use in CRC prevention (10-14). In particular, estrogen protective activities are thought to be related to their receptor subtype beta (ER- $\beta$ ), suggesting the use of selective ER- $\beta$ agonists in primary CRC prevention .

Since the early 80 s, the role of a progressive silencing of Estrogen Receptor beta (ER $\beta$ ) expression in intestinal cells, as a pathogenetic factor involved in intestinal tumorigenesis and its progression to an overt cancerous phenotype, has been studied in both animal models and clinical settings (11-14).

There is some evidence supporting ER- $\beta$ as a prognostic factor in sporadic adenocarcinoma, and suggesting its role as a relevant surrogate biomarker in the follow-up of intestinal neoplasia development and dysplastic severity (15-18).

In the ApcMin/+ mouse, that represents the animal model equivalent to FAP in humans, the loss of apoptotic control also occurs in non adenomatous (normal) mucosa, again depending upon a decreased ER- $\beta$ expression and related decreased TUNEL and caspase- 3 expression. In intact male $\mathrm{Apc}^{\mathrm{Min} /+}$ mice it has been demonstrated that supplementing the diet with selected, weak but specific ER- $\beta$ agonists reversed the hyperproliferative behavior in non adenomatous mucosa, and reduced the number and the degree of polyp dysplasia in adenomatous mucosa (19).

In human sporadic polyps, a progressive, significant decrease of ER- $\beta$ expression has been demonstrated, a finding confirmed in subjects affected by Familial Adenomatous Polyposis (FAP) (4). In these patients, in fact, a progressive, significant decrease of ER- $\beta$ expression was observed in the different stages of the disease, correlated with apoptosis $(r=0.76, p<$ 0.001), and inversely correlated with cell proliferation.

\section{Phytoestrogens and CRC}

Phytoestrogens are heterocyclic, non steroid phenols extracted from plants. These compounds are structurally similar and have a functional action as estrogen-agonists in mammals. Four classes of phytoestrogens can be distinguished, on the basis of their different molecular structure and different biological activities, namely isoflavones, lignans, coumestans and lactones (20-21).

Isoflavones, including genistein and quercitin, are the most known phytoestrogens. They are primarily found in the Fabaceae family, which includes legumes, soybean, peanut and clover.

Lignans were first identified in plants and later in biological fluids of mammals. These compounds are found in whole grain, seeds, fruits and vegetables but also in beverages such as coffee and tea (22). The cyclic urinary excretion of these phenolic compounds during the menstrual cycle led to investigations of their biological role, and they are now considered as a new hormone class (23).

Coumestans are less common in the human diet than isoflavones; they are extracted from fodder, clover, legumes and soybean. 
Lactones are the least common phytoestrogens in the human diet.

Natural phytoestrogens undergo glycosidic binding to carbohydrates to produce complex molecules that are hard for the intestinal tract to absorb. For this reason, after ingestion, this glycosidic binding is broken up by glycosidases, enzymes produced by intestinal microflora. This enzymatic digestion generates "aglycone", a compound that is quickly absorbed and can bind ERs (24).

Phytoestrogens are characterized by a higher binding affinity to ER- $\beta$ as compared to the other estrogen receptor subtype, alpha (ER-a). This biological characteristic explains why the administration of phytoestrogens does not produce the classic side effects associated to estrogen administration (cerebro- and cardiovascular attacks, a higher incidence of endometrial and breast cancer) (25-27), making these substances ideal candidates for CRC prevention.

As proposed for estrogens, genomic and non-genomic mechanisms have been also suggested for phytoestrogens to explain their biological activities $(20 ; 28-32)$.

One of the most interesting compounds is Silymarin, initially extracted from Silybum marianum. It is a mixture of four flavolignans (silibinin, isosilibinin, silydianin and silychristin) and the isoflavone taxifolin. It is already used in the treatment of alcoholic liver disease and as an anti-fibrotic agent (33).

Extensive research within the last decade has shown that silymarin can suppress the proliferation of a variety of tumor cells (e.g., prostate, breast, ovary, colon, lung, bladder); this is accomplished through cell cycle arrest at the G1/S-phase, induction of cyclindependent kinase inhibitors (such as p15, p21 and p27), down-regulation of anti-apoptotic gene products (e.g., Bcl-2 and $\mathrm{Bcl}-\mathrm{xL}$ ), inhibition of cell-survival kinases (AKT, PKC and MAPK) and inhibition of inflammatory transcription factors (e.g., NF-kappaB). Silymarin can also down-regulate gene products involved in the proliferation of tumor cells (cyclin D1, EGFR, COX-2, TGF-beta, IGF-IR), invasion (MMP-9), angiogenesis (VEGF) and metastasis (adhesion molecules). The antiinflammatory effects of silymarin are mediated through suppression of NF-kappaB-regulated gene products, including COX-2, LOX, inducible iNOS, TNF and IL-1 (35).

Silymarin has also been shown to sensitize tumors to chemotherapeutic agents through down-regulation of the MDR protein and other mechanisms. It binds to both estrogen and androgen receptors, and down-regulates PSA. In addition to its chemopreventive effects, silymarin exhibits antitumor activity against human tumors (e.g., prostate and ovary) in rodents (35)

Seidlova-Wuttke et al. (34) have demonstrated the selective binding of silymarin to ER- $\beta$ and no binding to ER- $\alpha$, but, how mentioned above, beyond its specific ER- $\beta$ agonism silymarin, exerts an anti 5-lipoxygenase (LOX) and anti-COX ${ }_{2}$ effect (35-36).

There is strong positive correlation has been recently established between 5-LOX overexpression and the appearance of typical high-risk factors for malignant transformation of polyps, such as histological epithelial localization, increased polyp size, villous and tubulovillous adenomas, high grade of intraepithelial neoplasia, and patient age because both inflammatory enzymes are up-regulated in colon carcinogenesis and involved in silencing apoptosis (37). 
Finally have been demonstrated that, without any apparent toxicity, the feeding of polyphenols from silymarin suppressed the tumor growth of the human SW480 CRC, implanted in $n u / n u$ mice. The inhibitory activity was associated with strong antiproliferative ( $\beta$-catenin, c-Myc and cyclin D1 suppression) and pro-apoptotic effects. (36).

Even lignans exert similar activity in several human cancers. For example Touillaud et al. examined associations between the risk of postmenopausal invasive breast cancer and dietary intakes of four plant lignans (pinoresinol, lariciresinol, secoisolariciresinol, and matairesinol) and estimated exposure to two enterolignans (enterodiol and enterolactone), as measured with a self-administered diet history questionnaire, among postmenopausal French women who were not taking soy isoflavone supplements. They demonstrate that high dietary intakes of plant lignans and high exposure to enterolignans were associated with reduced risks of Estrogen receptor negative and Progesteron receptor positive postmenopausal breast cancer in a Western population that does not consume a diet rich in soy (56). On the other hand Kuiisten et al. studied the associations between plasma enterolignans and the risk of colorectal adenomas in a Dutch case-control study . Colorectal adenomas are considered to be precursors of colorectal cancer. Cases with at least one histologically confirmed colorectal adenoma and controls with no history of any type of adenoma were included. Plasma enterodiol and enterolactone concentrations were measured by liquid chromatography with tandem mass spectrometry and they observed a substantial reduction in colorectal adenoma risk among subjects with high plasma concentrations of enterolignans, in particular, enterodiol (42).

Lignans exert a similar activity in several human colon cancer cells and are easily metabolized and absorbed in the colon (38-41). Lignin is a documented absorbant of carcinogens in the intestinal lumen. Its degradation to enterolignans by human intestinal microbiota could delay lignan release (42).

\section{Phytoestrogens in experimental CRC}

Mice with the Apc gene $\left(\mathrm{Apc}^{\mathrm{Min} /+}\right)$ mutation are highly susceptible to spontaneous intestinal adenoma formation and are therefore considered the most suitable model for experimental CRC studies (43). A recent experimental study demonstrated that in ovariectomized $\mathrm{Apc}^{\mathrm{Min} /+}$ female mice, the administration of a diet enriched with the phytoestrogen cumestrol induced a reduction of the number of polyps and an increased enterocyte migration as compared to control animals. Cumestrol was chosen in this study because it is a potent ER- $\beta$ agonist, with a 200-fold higher affinity than estradiol (44).

Seidlova-Wuttke et al. (34) compared the effect of silymarin and estradiol in ovariectomized female mice and confirmed the selective binding of silymarin to ER- $\beta$ by in vitro experiments. In another study, conducted by Khono et al., a silymarin-enriched diet significantly reduced azoxymethane-induced intestinal carcinogenesis in male mice. This effect was dose-dependent and determined a reduction of the number of cryptic adenomas, that are known to precede the development of colic adenocarcinoma (45).

The effect of a $0.02 \%$ silymarin-enriched diet on tumor development was also tested in intact $\mathrm{Apc}^{\mathrm{Min} /+}$ male mice, i.e. in physiological conditions. Intestinal polyp development was evaluated together with ER- $\beta$ expression, as well as other biological parameters influencing tumor growth (epithelial cell proliferation, apoptosis and migration), following the addition 
of a combination of the ER- $\beta$-selective agonist silymarin and/or lignin to a high-fat/lowfiber diet, which has been shown to foster tumor growth. The addition of silymarin or lignin to the diet and, to an even greater extent, the specific combination of the two, significantly counteracted intestinal tumorigenesis and increased ER- $\beta$ mRNA and protein levels. Cell proliferation and apoptosis were rebalanced and cell migration accelerated, restoring values similar to those observed in wild type animals. These results further support a protective effect of ER- $\beta$ in CRC, suggesting that dietary supplementation with the combination of silymarin and lignin could be a potential approach to CRC prevention (46).

\section{Phytoestrogens in human CRC}

Several studies have reported a reduction of the CRC risk associated with the consumption of soy foods (the main source of isoflavones) and non-fermented soy foods (e.g. tofu) (4752). The main limitations of these studies are that they all assessed only specific soy foods intake rather than total phytoestrogen intake: none of the studies was designed to evaluate phytoestrogen intake.

Another study investigated the association between colorectal cancer and lignans commonly present in Western diets. Dietary lignan intake produced a significant reduction in colorectal cancer risk (53).

Few epidemiologic studies have been conducted on the relationship between phytoestrogens and colorectal polyps formation. A case-control study on the role of lignans (54) suggests that these compounds may be protective against cardiovascular diseases and polyps (55).

Our research group aimed to assess whether a specifically ER $\beta$-targeted dietary management of human, recurrent sporadic adenopolyposis could have any impact on ER $\beta$ controlled apoptosis and/or proliferative behavior. As a preliminary step, we assessed whether non adenomatous (normal) mucosa of patients affected by sporadic adenopolyposis displayed an impaired apoptotic control of cell proliferation, dependent upon a reduced ER- $\beta$ expression similar to that observed in the $\mathrm{Apc}^{\mathrm{Min} /+}$ mouse. We designed a randomized, double blind placebo-controlled study to further assess whether a proprietary blend of ER- $\beta$ agonists (a mixture of silymarin, $30 \%$ of which as silibinin) could positively affect the ER $\beta$-dependent apoptotic control of cell proliferation, in the normal mucosa of patients affected by sporadic adenopolyposis, prone to polyp recurrence, and enrolled in a surveillance program for the follow-up of polyp recurrence by screening colonoscopy every 3-5 years.

We also assessed urinary phytoestrogens to check for compliance to sylimarin supplementation, and to see whether biomarkers expression was differently related to the phytoestrogens from the regular diet as opposed to the supplements given during the study period, in the two study groups. All patients were instructed to maintain their regular diet over the study period. Urinary phytoestrogens $(\mathrm{ng} / \mathrm{mL})$, namely the active lignans: enterodiol (ED) and enterolactone (EL), were measured on spot urinary samples.

In this clinical trial, we similarly hypothesized a ER $\beta$ down-modulation, paving the way for an altered apoptotic control of cell proliferation, in the non adenomatous colon mucosa of 
patients affected by sporadic adenopolyposis, presenting with a similar cell proliferation rate. We found that the normal mucosa of an APC-mutated intestinal environment is prone to polyp development and recurrence because of an altered proliferation-apoptosis ratio, related to a decreased ER- $\beta$ expression. Moreover, we demonstrated that ER- $\beta$ dependent apoptosis can be restored by administering specific phytoestrogens supplements with a selective action on ER $\beta$, in a similar manner to what we had previously observed in $\mathrm{Apc}^{\mathrm{Min} /+}$ mice. This randomized, double-blind placebo-controlled study showed that sylimarin, lignans and lignin can positively affect the ER $\beta$-driven apoptotic control of colon epithelial turnover, by increasing ER- $\beta$ expression in the normal mucosa of sporadic adenopolyposis patients prone to polyp recurrence. This is achieved via an increased ER $\beta$ content and was demonstrated in all patients, regardless of whether they were free from polyps or not, at screening colonoscopy.

\section{References}

[1] Van Engeland M, Derks S, Smits KM, Meijer GA, Herman JG (2011) Colorectal cancer epigenetics: complex simplicity. J Clin Oncol. 2011 29(10):1382-91

[2] Vogelstein, B. et al. (1988). N. Engl. J. Med., 319, 525-532.. (1988) Genetic alteration during colorectal-tumor development.

[3] Yang, K. et al. (1998) Dietary modulation in a mouse model for human familial adenomatous polyposis. Cancer Res., 58, 5713-5717.

[4] Barone M, Scavo MP, Papagni S, Piscitelli D, Guido R, Di Lena M, Comelli MC, Di Leo A. 2010 ER $\beta$ expression in normal, adenomatous and carcinomatous tissues of patients with familial adenomatous polyposis.Scand J Gastroenterol. Nov;45(11):1320-8. Epub

[5] Pettersson, $\mathrm{K}$ et al. 2000 Estrogen receptor beta acts as a dominant regulator of estrogen signaling Oncogene 19(8):4970-497). 19(8):4970-4978

[6] Menasce LP et al. (1993) Localization of the estrogen receptor locus (ESR) to chromosome 6q25.1 by FISH and a simple post-FISH banding technique.Genomics 17(1):263-265

[7] Weihua $Z$ et al. (2000) Estrogen receptor (ER) beta, a modulator of ERalpha in the uterus. Proc Natl Acad Sci USA 97(11):5936-5941.

[8] Nelson LR et. al. Bulun SE (2001) Estrogen production and action. J Am Acad Dermatol 45(1):S116-S124

[9] Galluzzo P. et al. (2007) 07) Role of ERbeta palmitoylation in the inhibition of human colon cancer cell proliferation. Endocr Relat Cancer 14(1):153-167

[10] Di Leo, A. et al. (1994). Prognostic value of cytosolic estrogen receptors in human colorectal carcinoma and surrounding mucosa. Preliminary results. Dig. Dis. Sci., 39, 2038-2042.

[11] Fernandez, E. et al. 1998 Hormone replacement therapy and risk of colon and rectal cancer. Cancer Epidemiol. Biomarkers Prev., 7, 329-333.

[12] Notarnicola, M. et al. (2001) Oestrogen receptors and microsatellite instability in colorectal cancer patients. Cancer Lett., 168, 65-70.

[13] Woodson, K. et al. (2001 Hormone replacement therapy and colorectal adenoma recurrence among women in the Polyp Prevention Trial. Report J. Natl Cancer Inst., 93, 1799-1805.

[14] Newcomb, P.A. et al. (2002). Postmenopausal hormone replacement therapy: scientific review. JAMA, 110, 219-227. 
[15] Lindberg, M.K. et al. 2003 Estrogenreceptor(ER)-betareduces ERalpharegulated gene transcription, supporting a "ying yang" relationship between ERalpha and ERbeta in mice. Mol. Endocrinol., 17, 203-208.

[16] Gustafsson, J.A. (1999) Estrogen receptor b: a new dimension in estrogen mechanism of action. J. Endocrinol., 163, 379-383.

[17] Giroux,V. et al. (2008) Estrogen receptor beta/deficiency enhances small intestinal tumorigenesis in ApcMin/p mice. Int. J. Cancer, 123,303-311.

[18] Kronenberg F, Fugh-Berman A (2002). Complementary and alternative medicine for menopausal symptoms. A review of randomized, controlled trials. Ann Intern Med 137(7):805-813

[19] Barone M, Tanzi S, Lofano K, et al. Dietary-induced ER $\beta$ upregulation counteracts intestinal neoplasia development in intact male $\mathrm{Apc}^{\mathrm{Min} /+}$ mice. Carcinogenesis 2010;31:269-274

[20] Matsuda H, et al. 2001 Phytoestrogens from the roots of Polygonum cuspidatum:structure requirement of hydroxyanthraquinones for estrogenic activity. Bioorg Mol Chem Lett 11(14):1839-184

[21] Whitten PL, Naftolin F (1998) Reproductive actions of phytoestrogens.Baillieres Clin Endocrinol Metab 12(4):667-690

[22] Adlercreutz H, Fotsis T, Heikkinen R, Dwyer JT, Goldin BR, Gorbach SL, Lawson AM, Setchell KD (1981) Diet and urinary excretion of lignans in female subjects. Med Biol 59(4):259-261

[23] Adlercreutz H, Höckerstedt K, Bannwart C, Bloigu S, Ha“ma“la“inen E, Fotsis T, Ollus A (1987) Effect of dietary components, including lignans and phytoestrogens, on enterohepatic circulation and liver metabolism of estrogens and on sex hormone binding globulin (SHBG). J Steroid Biochem 27(4-6):1135-1344

[24] Otieno DO, Shah NP (2007) Endogenous beta-glucosidase and beta-galactosidase activities from selected probiotic microorganisms and their role in isoflavone biotransformation in soymilk.J Appl Microbiol 103(4):910-91

[25] Kronenberg F, Fugh-Berman A (2002) Complementary and alternative medicine for menopausal symptoms. A review of randomized, controlled trials. Ann Intern Med 137(7):805-813

[26] Setchell KD (1998) Phytoestrogens: the biochemistry, physiology and implications for human health of soy isoflavones. Am J Clin Nutr 68(6 Suppl):1333s-1146s

[27] Kuiper GGJM et al Lemmen JG, Carlsson B et al (1996) Interaction of estrogenic chemicals and phytoestrogens with estrogen receptor beta. Endocrinology 139(10):4252-4263

[28] Anderson JJB, Anthony M, Messina M, Garner SC (1999) Effect of phytoestrogens on tissues. Nutr Res Rev 12(3):75-116

[29] Adlercreutz $\mathrm{H}$ et al (2000) Food containing phytoestrogens, and breast cancer. Biofactors 12(1-4):89-93

[30] Santti R, Makela S, Strauss L, Korkman J, Kostian ML (1998) Phytoestrogens: potential endocrine disruptors in males. Toxicol Ind Health 14(1-2):223-237

[31] Messina MJ, Loprizi CL (2001) Soy for breast cancer survivors: a critical review of the literature. J Nutr 131(11 Suppl):3095s-3108s

[32] Kurzer MS (2002) Hormonal effects of soy in premenopausal women and men. J Nutr 132(3):570s-573s 
[33] Polyak,S.J. et al. (2007) Inhibition of T-cell inflammatory cytokines, hepatocyte NFkappaB signaling, and HCVinfection by standardized Silymarin.Gastroenterology, 132, 1925-1936.

[34] Wuttke-Seidlova D, Becker T, Cristoffel V, Jarry H, Wuttke W (2003) Silymarin is a selective estrogen receptor beta (ER beta) agonist and has estrogenic effects in the metaphysis of the femur but no antiestrogenic effects in the uterus of ovariectomized rats.J Steroid Biochem Mol Biol 86(1):179-188

[35] Agarwal R, Agarwal C, Ichikawa H, et al. 2006 Anticancer potential of silymarin: from bench to bed side. Anticancer Res;26:4457-98.

[36] Velmuragan B. et al. 2010 Silibinin exerts sustained growth suppressive effect against human colon carcinoma SW480 xenograft by targeting multiple signaling molecules. Pharm Res;27:2085-2097.

[37] Wasilewiwicz M et al. 2010 Overexpression of 5-lipoxygenase in sporadic adenomas and a possible new aspect of colon carcinogenesis. Int J Colorectal Dis;25:1079-1085.

[38] Begum A et al. 2004 Dietary lignins are precursors of mammalian lignans in rats. J Nutr;134:120-12.

[39] Rajamanickam S, Agarwal R. 2008 Natural products and colon cancer: current status and future prospects. Drug Dev Res;69:460-471.

[40] Kuijsten A, et al. 2006 Plasma enterolignans are associated with lower colorectal adenoma risk. Cancer Epidemiol Biomarkers Prev;15:1132-1136.

[41] Touré A, Xueming X. 2010 Flaxseed lignans: source, biosynthesis, metabolism, antioxidant, bio-active components, and health benefits. Compreh Rev Food Sci Food Safety;9:261-269

[42] Mueller S, Simon S, Chae K, et al. 2004 Phytoestrogens and their human metabolites show distinct agonistic and antagonistic properties on Estrogen Receptor a (ERa) and ER $\beta$ in Human Cells. Toxicol Sci;80: 14-25

[43] Moser, A.R. et al. (1990) A dominant mutation that predisposes to multiple intestinal neoplasia in the mouse. Science, 247, 322-324.

[44] Javid, S.H. et al. (2005) Modulation of tumor formation and intestinal cell migration by estrogens in the ApcMin/p mouse model of colorectal cancer. Carcinogenesis, 26, 587-595.

[45] Khono $\mathrm{H}$ et al. 2002 Silymarin, a naturally occurring polyphenolic antioxidant flavonoid, inhibits azoxymethane-induced colon carcinogenesis in male F344 rats. Int J Cancer 101(5):461-468

[46] Michele Barone et al. (2010). Dietary-induced ERb upregulation counteracts intestinal neoplasia development in intact male ApcMin/1 mice. Carcinogenesis vol.31 no.2 pp.269-274

[47] Grodstein F et al. 1998. Postmenopausal hormone use and risk for colorectal cancer and adenoma. Ann Intern Med 128(9):705-712

[48] Hoshiyama Y et al. (1993) A case-control study of colorectal cancer and its relation to diet, cigarettes, and alcohol consumption in Saitama Prefecture, Japan. Tohoku J Exp Med 171(2):153-165

[49] Jacobson JS et al. 1996. Hormone replacement therapy is associated with lower risk of adenomatous polyps of the large bowel: the Minnesota cancer prevention research unit case control study.Cancer Epidemiol Biomarkers Prev 5(10):779-784 
[50] Peipins A, Newman B, Sandler RS (1997) Use of exogenous hormones and risk of colorectal adenomas. Cancer Epidemiol Biomarkers Prev 6(4):671-675

[51] Weyant MJ, Carothers AM, Mahmoud NN et al (2001) Reciprocal expression of ERalpha and $\mathrm{ERb}$ is associated with estrogen-mediated modulation of intestinal tumorigenesis. Cancer Res 6(1):2547-2551

[52] Theodoratou E. et al. (2007) Dietary flavonoids and the risk of colorectal cancer. Cancer Epidemiol Biomarkers Prev 16(4):684-693

[53] Cotterchio $M$ et al. (2006) Dietary phytoestrogen intake is associated with reduced colorectal cancer risk. J Nutr 136(12):3046-3053

[54] Axelson M, Sjo“vall J, Gustafsson BE, Setchell KD (1982) Origin of lignans in mammals and identification of a precursor from plants. Nature 298(5875):659-660

[55] Kuijsten A, Arts ICW, Holmann PCH, van't Veer P, Kampman E (2006) Plasma enterolignans are associated with lower colorectaladenoma risk. Cancer Epidemiol Biomarkers Prev 15(6):1132-1136

[56] Touillaud, M.S. et al. (2007) Dietary lignan intake and postmenopausal breast cancer risk by estrogen and progesterone receptor status. J. NatlCancer Inst., 99, 475-486

[57] Di Leo Alfredo et al. (2011) Human sporadic adenocarcinoma and dietary management of Estrogen Receptors (ERs)-driven biomarkers of proliferation and apoptosis (Ki67; caspase 3, TUNEL) in the colorectal mucosa of patients undergoing screening colonoscopy. Submitted to GASTROENTEROLOGY. 


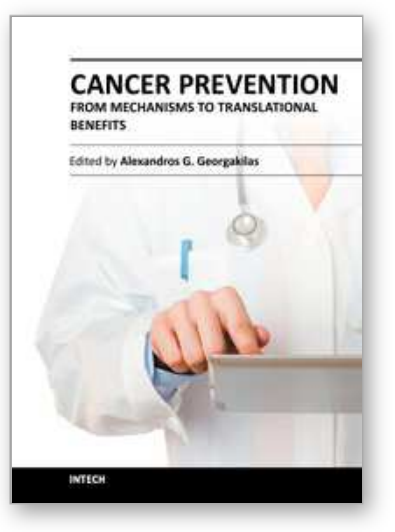

\author{
Cancer Prevention - From Mechanisms to Translational Benefits \\ Edited by Dr. Alexandros G. Georgakilas
}

ISBN 978-953-51-0547-3

Hard cover, 476 pages

Publisher InTech

Published online 20, April, 2012

Published in print edition April, 2012

This unique synthesis of chapters from top experts in their fields targets the unique and significant area of cancer prevention for different types of cancers. Perspective readers are invited to go through novel ideas and current developments in the field of molecular mechanisms for cancer prevention, epidemiological studies, antioxidant therapies and diets, as well as clinical aspects and new advances in prognosis and avoidance of cancer. The primary target audience for the book includes PhD students, researchers, biologists, medical doctors and professionals who are interested in mechanistic studies on cancer prevention and translational benefits for optimized cancer treatment.

\title{
How to reference
}

In order to correctly reference this scholarly work, feel free to copy and paste the following:

Michele Barone, Raffaele Licinio and Alfredo Di Leo (2012). Phytoestrogens as Nutritional Modulators in Colon Cancer Prevention, Cancer Prevention - From Mechanisms to Translational Benefits, Dr. Alexandros G.

Georgakilas (Ed.), ISBN: 978-953-51-0547-3, InTech, Available from:

http://www.intechopen.com/books/cancer-prevention-from-mechanisms-to-translational-

benefits/phytoestrogens-as-nutritional-modulators-in-colon-cancer-prevention

\section{INTECH}

open science | open minds

\section{InTech Europe}

University Campus STeP Ri

Slavka Krautzeka 83/A

51000 Rijeka, Croatia

Phone: +385 (51) 770447

Fax: +385 (51) 686166

www.intechopen.com

\section{InTech China}

Unit 405, Office Block, Hotel Equatorial Shanghai

No.65, Yan An Road (West), Shanghai, 200040, China

中国上海市延安西路65号上海国际贵都大饭店办公楼 405 单元

Phone: +86-21-62489820

Fax: +86-21-62489821 
(C) 2012 The Author(s). Licensee IntechOpen. This is an open access article distributed under the terms of the Creative Commons Attribution 3.0 License, which permits unrestricted use, distribution, and reproduction in any medium, provided the original work is properly cited. 